\title{
Modified bedside twist drill craniostomy for evacuation of chronic subdural haematoma
}

\author{
Tomasz Szmuda, Sara Kierońska, Paweł Słoniewski, Jarosław Dzierżanowski
}

Department of Neurosurgery, Medical University of Gdansk, Gdansk, Poland

Videosurgery Miniinv 2019; 14 (3): 442-450

DOI: https://doi.org/10.5114/wiitm.2019.83001

\begin{abstract}
Introduction: Standard craniotomy $(\mathrm{SC})$ and burr hole craniostomy $(\mathrm{BHC})$ are regarded as the standard approaches to chronic subdural haematoma (CSDH). Bedside twist drill craniostomy (TDC), performed at the patient's bedside, was introduced as an alternative to the standard methods. However, clinical and radiological features of patients treated with TDC and BHC/SC have not been compared.

Aim: To demonstrate the specific features of CSDH that affect the surgeons' preferences when selecting patients for TDC. Material and methods: A retrospective analysis of 32 patients treated due to CSDH in the year 2017 at a single institution was performed. Baseline radiological characteristics, clinical status at admission, complication rate and clinical outcomes were compared between BHC/SC and TDC.

Results: Of the 32 patients, 5 (15.6\%) were treated using TDC and 27 (84.4\%) by SC or BHC. The duration of the $T D C$ procedure was significantly shorter than the time of standard therapies $(p<0.01)$. There were no differences between TDC and BHC/SC in terms of baseline clinical characteristics, including age, gender, head trauma history, diabetes, hypertension, antiplatelet drug use, clinical manifestation and the Glasgow Coma Scale score (all $p>0.05$ ). Patients treated with TDC had a significantly thicker haematoma (TDC vs. BHC/SC: mean $25.3 \mathrm{~mm}$ vs. $14.6 \mathrm{~mm}$ ) $(p<0.01)$ and demonstrated a smaller midline shift (TDC vs. BHC/SC: mean $0.5 \mathrm{~mm}$ vs. $4.0 \mathrm{~mm})(p=0.01)$ compared to those treated with BHC/SC.

Conclusions: Twist drill craniostomy is a more effective method for CSDH evacuation compared to SC and BHC. This procedure is considered as the first line treatment for patients with a thicker and non-septated haematoma, and with a smaller midline shift.
\end{abstract}

Key words: craniotomy, chronic subdural haematoma, bedside twist drill craniostomy, twist drill craniostomy, burr hole craniostomy.

\section{Introduction}

Chronic subdural haematoma (CSDH) is a frequently occurring disease with an incidence of 1.7 to as high as 13.3 cases per 100000 [1-3]. Advanced age (> 70), alcohol abuse, male sex, seizures or anticoagulation therapy markedly increases CSDH occurrence $[2,4,5]$. Some authors have reported that vitamin $\mathrm{K}$ antagonists cause a 3 -fold increase in the risk of subdural haematoma, compared with antiplatelet therapy and with factor Xa inhibitors [6-8]. In the recent decade, CSDH has become of concern among elderly patients partially due to their frequent use of anticoagulation therapy.

Chronic subdural haematoma can be treated by three surgical approaches: twist drill craniostomy (TDC), burr hole craniostomy (BHC) or standard craniotomy (SC). Currently there is a lack of evidence, 
such as prospective randomised trials, demonstrating the superiority of any method in terms of mortality and efficacy [9]. On the other hand, $\mathrm{BHC}$ is initially the most commonly preferred treatment approach as revealed by a nationwide British study [9].

Bedside TDC is an attractive alternative to standard therapies such as BHC and SC, although rarely attempted in Eastern Europe [10]. Minimal invasiveness, shorter hospitalisation, no need for general anaesthesia or an operating room are some of the benefits of TDC [11-19]. As noted by others, TDC is associated with severe complications including acute intracranial bleeding [6]. In the early 2000s TDC was noted to have a higher rate of recurrence than $\mathrm{BHC}$ [1]. On the other hand, recent prospective studies supported either TDC or BHC as a primary treatment method [17, 20]. Despite the typical learning curve and the potential advantages of bedside procedures, there has been a general reluctance of the neurosurgical community to adopt TDC.

The content of CSDH could be compartmentalized by fibrin septa that hinder sufficient drainage of the entire haematoma. In such cases, SC with membranectomy is considered superior to $\mathrm{BHC}$ or TDC [21]. Recently, endoscopic BHC was proven safe and more effective in the removal of the membranes with fewer complications such as drainage failures or recurrences. However, endoscopic membranectomy is technically challenging and should be performed by a skilled surgeon [22].

\section{Aim}

To date, $\mathrm{CSDH}$ cases treated with TDC and $\mathrm{BHC} / \mathrm{SC}$ have not been extensively compared in terms of their clinical and radiological features. Anecdotally, it seems that older patients, those with comorbidities and harbouring non-septated CSDH can be easily treated with TDC. Therefore we aimed to examine whether the surgeons' decisions to qualify CSDH patients for SC, BHC or TDC were correlated with any patient characteristics or radiological features of the haematoma.

\section{Material and methods}

Patients treated at a single institution due to CSDH were retrospectively reviewed the same year the TDC method was introduced there (2017). Ultimately 5 patients underwent TDC and another 27 were treated using $\mathrm{BHC}$ or SC. In the TDC group there were 3 males and 2 females; the median age was 69 years (47-84). The BHC or SC group consisted of 20 (74\%) males and 7 (26\%) females; the median age was 72.2 years (52-91 years).

Pre-operative computed tomography (CT) scans were reviewed and classified according to the following features: (1) density (either isodense or hypodense relative to the parenchyma); (2) presence and thickness of the CSDH's outer membrane; (3) thickness of the CSDH; (4) midline shift; (5) presence of septated compartments; (6) location of haematoma (uni-/bilateral) and (7) side. A follow-up $\mathrm{CT}$ was done within $24 \mathrm{~h}$ after surgery. The volume of haematoma was evaluated on both pre- and post-operative CT using RadiAnt DICOM Viewer v. 4.6.5 (Medixant, Poland).

\section{The TDC procedure}

All TDC procedures were performed using the Subdural Evacuating Port System (Medtronic, Tulsa, USA) under local anaesthesia $(\sim 10 \mathrm{ml}$ of $1 \%$ lidocaine) in the neurosurgery department's small procedures room. Complete and disposable kits included hand drill, fenestrated drain and suturing material. Haematomas were evacuated via a port. The burr hole position was identified anterior to the area of greatest subdural fluid thickness in the preoperative CT. Following a $5 \mathrm{~mm}$ linear incision of the skin, subcutaneous tissue, galea and periosteum, a self-retaining scalp retractor was applied to expose the skull. The drill bit was secured with a safety stop collar. A burr hole was made by a twist drill through the outer and inner tables of the skull using a 3 or $5 \mathrm{~mm}$ pointed tip drill bit. The modified drilling technique was adopted from Yadav et al. [16]. An angle of $60^{\circ}$ to $90^{\circ}$ to the outer table of the skull was chosen. Drilling included subdural membranes and was stopped until fluid outflow, then the evacuating port was inserted (silicone tube by Medtronic, Tulsa, USA). A suction reservoir bulb was attached to one end of the tube and a low homogeneous negative pressure was applied. If feasible, the patient was positioned in the $30^{\circ}$ Trendelenburg position. An antiseptic ointment was generously applied around the base of the port, followed by placing a sterile dressing. Fluid evacuation was completed within 24-48 h until full fluid evacuation was confirmed in a CT scan. During this period, the suction reservoir bulb was monitored and emptied as needed with repeated reapplication of low negative pressure (Photo 1 ). 

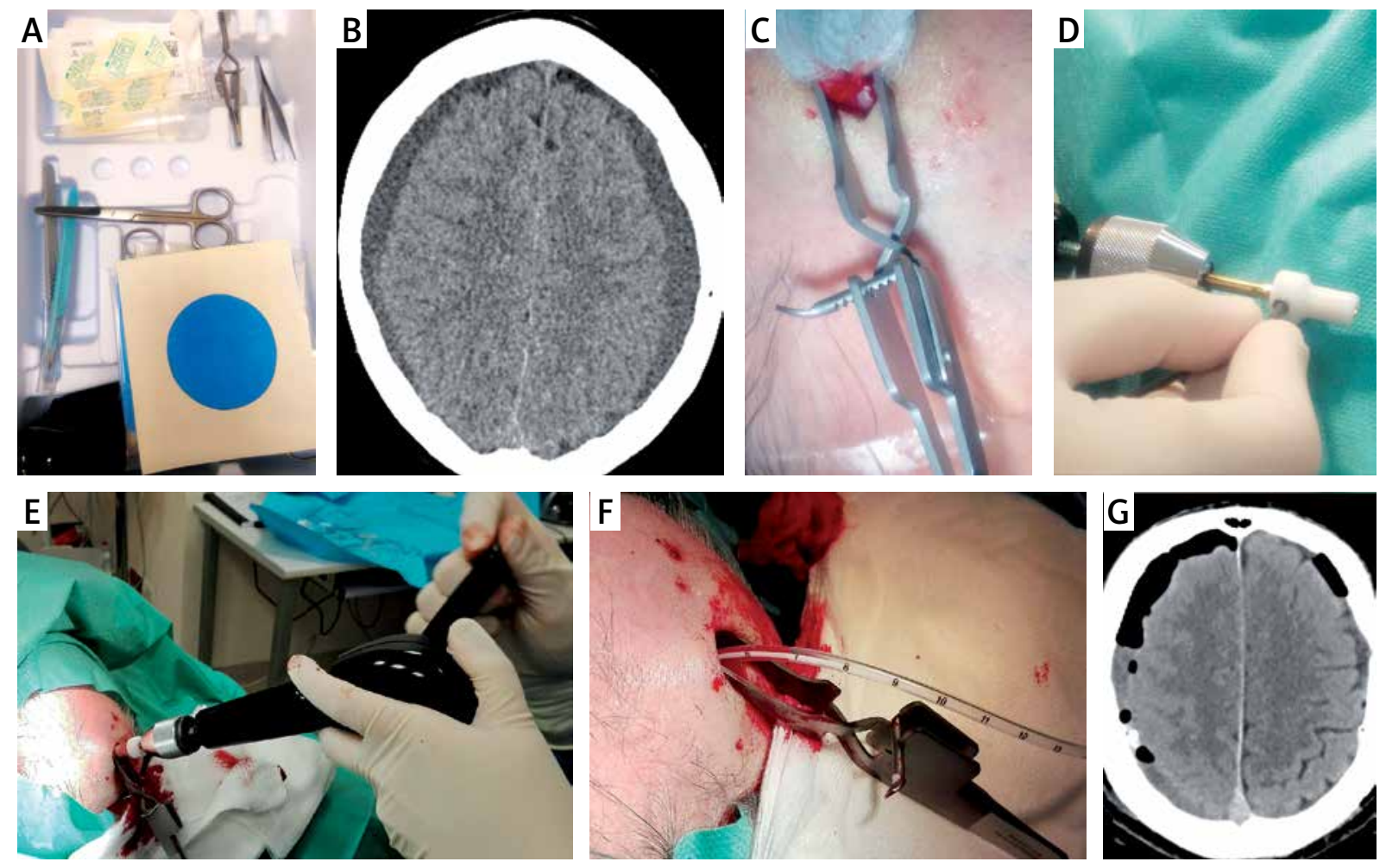

Photo 1. Awake twist drill craniostomy technique. The set including all tools required for entire procedure (A). The patient with bilateral hypodense chronic subdural haematoma (CSDH) was qualified for twist drill craniostomy (TDC) (B). Following local anaesthesia and skin incision a disposable self-retaining scalp retractor was applied (C). Placing the safety stop collar (D) should precede hand burr hole drilling (E). Thereafter the subdural space could be drained using a silicone drain $(\mathbf{F})$. The postoperative computed tomography imaging showed a residual CSDH and moderate pneumocephalus (G)

\section{Independent factors}

Factors determining the surgeon's selection of treatment modality between SC, BCH and TDC were divided into clinical and radiographic features.

The clinical factors included age, sex, clinical status at admission (according to Glasgow Coma Scale - GCS), timing of surgery after trauma, past medical history and concomitant medications. The final clinical outcome at discharge was categorized using the Glasgow Outcome Scale (GOS). Total time of hospital stay was not compared between the TDC and $\mathrm{BHC} / \mathrm{SC}$ groups, because it is generally influenced by each individual patient's condition at admission. The baseline radiographic factors were evaluated on CT imaging.

\section{Statistical analysis}

Univariate analyses were performed using Pearson's correlation, Mann-Whitney $U$ test for contin- uous variables or $\chi^{2}$ test for categorical variables. Binary logistic regression analysis was then used to dichotomize the outcome as a variable dependent on variables which had $p>0.25$ in the univariate analysis. The level of statistical significance was set at $p<0.05$.

\section{Results}

\section{Procedure}

In patients with unilateral CSDH the mean duration of the bedside TDC procedure $(27.0 \pm 37.3 \mathrm{~min}$; min.-max. 24-30 min) was significantly shorter $(p<0.01)$ than that of the standard methods SC/BHC (86.6 $\pm 34.1 \mathrm{~min}$; min.-max. 43-135 min). However, there were no significant differences $(p=0.27)$ in the duration of surgery between TDC and the standard approaches for bilateral haematomas (TDC: $46.0 \pm 1.4 \mathrm{~min}$; min. $-\max .45-47$ min vs. SC/BHC: $85.5 \pm 37.5 \mathrm{~min}$; min. $-\max .59-112 \mathrm{~min})$. The mean 
duration of subdural catheter indwelling was 2 days, regardless of the chosen method.

\section{Complications}

We did not note any major complications such as acute epi- or subdural bleeding. One patient developed intracerebral haematoma during the postoperative period. Non-tension pneumocephalus developed postoperatively in one patient treated with TDC ( 1 of $5 ; 20.0 \%$ ), compared to 4 and 6 patients who were treated with $\mathrm{BHC}$ and $\mathrm{SC}$ respectively $(10$ of $27 ; 37.0 \%)(p=0.46)$. Two patients were re-operated on due to wound infection, one following BHC and another following SC. Two patients suffered postoperative seizures after BHC, another 5 patients after craniotomy, whereas none did after TDC.

\section{Baseline characteristics}

The most common presenting symptoms were headache, dizziness, and vomiting, whereas paresis was observed in $40.6 \%$ of patients. No significant differences were noted between groups (TDC vs. SC/BHC) in terms of symptoms, comorbidities, anticoagulants, antiplatelet therapy and history of head injury. Sixty percent and $3.7 \%$ of patients qualified for respectively TDC and SC/BHC had a history of subdural haematoma (SDH) surgery, although the difference was not significant $(p=0.06)$ (Table I).

Table I. Baseline clinical characteristics

\begin{tabular}{|c|c|c|c|c|}
\hline Baseline clinical characteristics & $\begin{array}{l}\text { Entire group } \\
\quad(n=32)\end{array}$ & $\begin{array}{c}\text { TDC } \\
(n=5)\end{array}$ & $\begin{array}{c}\text { Craniotomy/ } \\
\text { burr hole }(n=27)\end{array}$ & $P$-value \\
\hline Age, mean \pm SD; min.-max. [years] & $\begin{array}{l}68.7 \pm 13.9 \\
25-87\end{array}$ & $\begin{array}{c}71.6 \pm 14.9 \\
51-87\end{array}$ & $\begin{array}{c}68.1 \pm 13.7 \\
25-83\end{array}$ & 0.61 \\
\hline Sex: males/females & $24 / 8$ & $3 / 2$ & $21 / 6$ & 0.58 \\
\hline \multicolumn{5}{|l|}{ Glasgow Coma Scale: } \\
\hline Mean \pm SD & $12.6 \pm 2.8$ & $13.6 \pm 2.6$ & $12.4 \pm 2.8$ & 0.39 \\
\hline $14-15$ & $17 / 32(53.1 \%)$ & $4 / 5(80.0 \%)$ & $13 / 27(48.1 \%)$ & 0.34 \\
\hline $9-13$ & $13 / 32(40.6 \%)$ & $1 / 5(20.0 \%)$ & $12 / 27(44.4 \%)$ & 0.62 \\
\hline$<9$ & $3 / 32(9.4 \%)$ & $0 / 5(0.0 \%)$ & $3 / 27(11.1 \%)$ & 1.00 \\
\hline \multicolumn{5}{|l|}{ Symptoms: } \\
\hline Headache & $18 / 32(56.2 \%)$ & $4 / 5(80 \%)$ & $14 / 27(51.8 \%)$ & 0.35 \\
\hline Dizziness & 19/32 (59.4\%) & $2 / 5(40.0 \%)$ & $17 / 27(63.0 \%)$ & 0.37 \\
\hline Vomiting & 18/32 (56.3\%) & $3 / 5(60.0 \%)$ & 15/27 (55.6\%) & 1.00 \\
\hline Paresis & $13 / 32(40.6 \%)$ & $1 / 5(20.0 \%)$ & $12 / 27(44.4 \%)$ & 0.62 \\
\hline \multicolumn{5}{|l|}{ Medical history: } \\
\hline Any comorbidity & 28/32 (87.5\%) & $4 / 5(80.0 \%)$ & $24 / 27(88.9 \%)$ & 0.51 \\
\hline DM & $17 / 32(53.1 \%)$ & $1 / 5(20.0 \%)$ & 16/27 (59.3\%) & 0.16 \\
\hline Arterial hypertension & 17/32 (53.1\%) & $1 / 5(20.0 \%)$ & 16/27 (59.3\%) & 0.16 \\
\hline COPD & 10/32 (31.3\%) & $1 / 5(20.0 \%)$ & 9/27 (33.3\%) & 1.00 \\
\hline Atrial fibrillation & $22 / 32(68.8 \%)$ & $3 / 5(60.0 \%)$ & 19/27 (70.4\%) & 0.63 \\
\hline History of SDH surgery & $3 / 32(9.4 \%)$ & $2 / 5(40.0 \%)$ & $1 / 27(3.7 \%)$ & 0.06 \\
\hline History of head injury & $20 / 32(62.5 \%)$ & $2 / 5(40.0 \%)$ & $18 / 27(66.7 \%)$ & 0.34 \\
\hline Anticoagulation therapy & $17 / 32(53.1 \%)$ & $3 / 5(60.0 \%)$ & $14 / 27(51.9 \%)$ & 1.00 \\
\hline
\end{tabular}

COPD - chronic obstructive pulmonary disease, CSDH - chronic subdural haematoma, TDC - twist drill craniostomy. 
Table II. Radiological characteristics

\begin{tabular}{|c|c|c|c|c|}
\hline Radiological characteristics & $\begin{array}{l}\text { Entire group } \\
\quad(n=32)\end{array}$ & $\begin{array}{l}\text { TDC } \\
(n=5)\end{array}$ & $\begin{array}{c}\text { Craniotomy/ } \\
\text { burr hole }(n=27)\end{array}$ & $P$-value \\
\hline Density: & & & & 0.51 \\
\hline Hypodense & 28/32 (87.5\%) & $4 / 5(80.0 \%)$ & $24 / 27(88.9 \%)$ & \\
\hline lodense & $4 / 32(12.5 \%)$ & $1 / 5(20.0 \%)$ & $3 / 27(11.1 \%)$ & \\
\hline Outer membrane of CSDH & $15 / 32(46.9 \%)$ & $1 / 5(20.0 \%)$ & $14 / 27(51.9 \%)$ & 0.34 \\
\hline $\begin{array}{l}\text { Thickness of outer membrane } \\
(\text { mean } \pm \text { SD; min.-max.) }[\mathrm{mm}]\end{array}$ & $\begin{array}{c}1.2 \pm 1.0 \\
0-3.0\end{array}$ & $\begin{array}{l}0.9 \pm 0.9 \\
0.5-2.5\end{array}$ & $\begin{array}{c}1.3 \pm 1.1 \\
0-3.0\end{array}$ & 0.43 \\
\hline $\begin{array}{l}\text { Thickness of entire CSDH } \\
(\text { mean } \pm \text { SD; min.-max.) }[\mathrm{mm}]\end{array}$ & $\begin{array}{c}16.3 \pm 6.4 \\
0.8-29.0\end{array}$ & $\begin{array}{l}25.3 \pm 1.6 \\
23.4-27.0\end{array}$ & $\begin{array}{l}14.6 \pm 5.4 \\
0.8-29.0\end{array}$ & $<0.01$ \\
\hline $\begin{array}{l}\text { Midline shift } \\
(\text { mean } \pm \text { SD; min.--max.) }[\mathrm{mm}]:\end{array}$ & $\begin{array}{l}3.4 \pm 2.9 \\
0-10.0\end{array}$ & $\begin{array}{l}0.5 \pm 1.0 \\
0-2.3\end{array}$ & $\begin{array}{l}4.0 \pm 2.8 \\
0-10.0\end{array}$ & 0.01 \\
\hline$>5 \mathrm{~mm}$ & $14 / 32(43.7 \%)$ & $0 / 5(0 \%)$ & $14 / 27(51.9 \%)$ & 0.04 \\
\hline$<5 \mathrm{~mm}$ & $18 / 32(56.3 \%)$ & $5 / 5(100 \%)$ & $13 / 27(48.2 \%)$ & \\
\hline Septated & 6/32 (18.8\%) & $0 / 5(0 \%)$ & $6 / 27(22.2 \%)$ & 0.55 \\
\hline \multicolumn{5}{|l|}{ Side: } \\
\hline Bilateral & $4 / 32(12.5 \%)$ & $2 / 5(40.0 \%)$ & $2 / 27(7.4 \%)$ & 0.11 \\
\hline Right & $16 / 32(50.0 \%)$ & $2 / 5(40.0 \%)$ & $14 / 27(51.9 \%)$ & 1.00 \\
\hline Left & $12 / 32(37.5 \%)$ & $1 / 5(20.0 \%)$ & $11 / 27(40.7 \%)$ & 0.63 \\
\hline
\end{tabular}

CSDH - chronic subdural haematoma, TDC - twist drill craniostomy.

\section{Radiology - baseline differences and outcome}

We found non-clinically significant air accumulation in both hemispheres in all postoperative CTs. The TDC

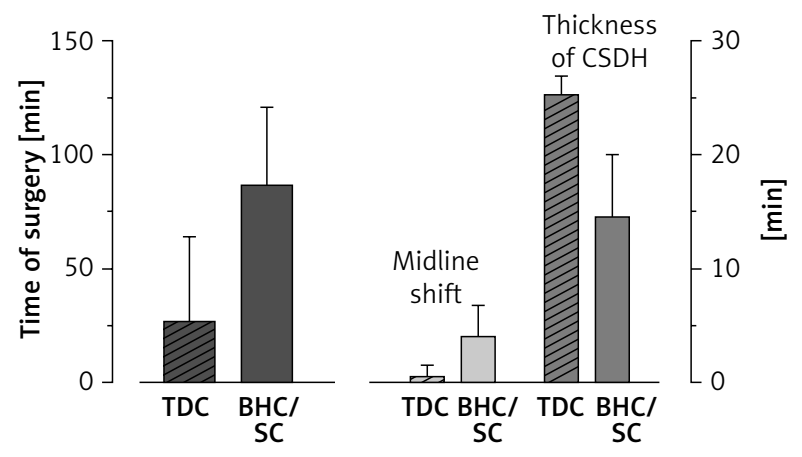

Figure 1. Significant differences between bedside twist drill craniostomy and standard treatments for chronic subdural haematoma. Time of the procedure for unilateral CSDH was significantly shorter in the case of TDC. Regarding baseline characteristics, patients with thicker haematoma and with smaller midline shift in computed tomography were offered TDC more often

CSDH - chronic subdural haematoma, SC - standard craniotomy, $B H C$ - burr hole craniostomy, TDC - twist drill craniostomy. group differed from the SC/BHC group in terms of several baseline radiological characteristics. All 6 patients with septated CSDH were treated with the standard craniotomy, although the difference was not significant $(p=0.55)$. Patients with thicker haematoma were offered TDC more often $(p<0.01)$. On the other hand, standard treatment (SC or $\mathrm{BHC}$ ) was preferred more often in patients with greater midline shift in CT $(p=0.01)$. Baseline density of haematoma, presence and thickness of CSDH outer membrane, uni-/bilateral haematoma, and side did not influence the surgeon's preference of TDC vs. standard treatment (Table II and Figure 1).

\section{Recurrence of haematoma}

Two patients harboured a recurrent CSDH following TDC (2 of $5 ; 40.0 \%$ ), whereas only 1 did in the SC/ $\mathrm{BHC}$ group $(p=0.06)$. In all patients with recurrent $\mathrm{CSDH}$ the symptoms relapsed after their discharge. In all patients with a CSDH relapse, the haematoma was evacuated by BHC.

\section{Final clinical outcome}

Five patients died, all from the SC group. There was no significant difference between SC/BHC and 
TDC in terms of mortality $(p=0.29)$. All five patients in the TDC group had favourable clinical outcome (GCS 14-15), compared to only 17 of 27 (62.9\%) from the SC/BHC group. The mean length of stay in the neurosurgery department was 3 days when TDC was performed, whereas it was 9 and 6 days following $\mathrm{SC}$ and $\mathrm{BHC}$ respectively $(p<0.01)$.

\section{Multivariate analysis}

None of the factors analysed using logistic regression were statistically significant $(p>0.05)$.

\section{Discussion}

The CSDH is a frequently encountered condition in neurosurgical practice [19]. An ageing population, increasing use of anticoagulants and antiplatelet medication, and greater availability of sophisticated head imaging are some of the factors that increase $\mathrm{CSDH}$ occurrence $[6,23]$. In the era of the minimally invasive approach to surgery, the development of simple techniques to manage CSDH seems desirable [20]. Currently the drainage of CSDH can be accomplished by SC or two craniostomy methods - BHC or TDC. Craniostomy is a less invasive procedure than $\mathrm{SC}$ and is regarded as the gold standard for symptomatic CSDHs. Lack of a clear consensus in the literature regarding the optimum treatment for $\mathrm{CSDH}$ gives the surgeons an opportunity to treat according to personal preferences. The TDC is the least invasive therapy for $\mathrm{CSDH}$, although it has several limitations, including the surgeon's personal opinion about TDC performed outside of the operating room [24, 25]. This study was undertaken to determine the factors influencing the surgeons' choice-SC, BHC or TDC.

Various efficacy measures have been used in studies assessing the course of CSDH, such as mortality, morbidity, recurrence rate and cure rate. In terms of mortality and morbidity, most of the large meta-analyses provide similar rates $[3,26,27]$. The authors of the above studies do not associate mortality with any therapeutic approach. On the other hand, the recurrence of haematoma is a meaningful outcome. A relapse of haematoma requires additional surgery, generates costs and increases the infection rate. Both techniques, TDC and BHC, have been compared in various studies across several years $[11,17,18,24,28]$. In the first meta-analysis, TDC significantly surpassed $\mathrm{BHC}$ in terms of recurrence (TDC $18.0 \%$ vs. BHC 39.0\%) [1]. Three recent meta- analyses demonstrated that recurrence rates are statistically the same for either BHC or TDC (relative risk $(R R)=1)[3,26,27]$. Moreover, the recurrence rate was similar for TDC and $\mathrm{BHC}$ in a prospective study (TDC $18.4 \%$ vs. BHC $11.1 \%$ ) which was not included in the former systematic reviews [11]. After applying sophisticated statistics, one team suggested that BHC is superior to TDC [28]. An observational study describing the largest number of patients so far $(n=233)$ showed that almost 33\% of patients require a re-operation (open surgical evacuation) [12]. Compared to BHC, TDC had a higher operative failure rate (defined by technical factors such as drain obstruction or other surgical complications) $(R R=0.35)$, although patients achieve higher cure rates $(R R=0.92)$ [26]. In other words, more patients improved neurologically due to TDC at the end of the follow-up period.

Since both methods had similar effectiveness, the surgeon selected between TDC and BHC according to his or her own preference [18]. The TDC ensures the safety of the patient during the procedure and can be done in the treatment room on the ward under local anaesthesia [15]. These factors represent a huge advantage of this technique. So what are the reasons for the widespread use of BHC (86\% of procedures, followed by SC 9\%) in Europe? [9, 29, 30]. In Poland almost all patients are offered either $\mathrm{BHC}$ or SC. Choosing the best operation for CSDH concerned authors in the past $[15,28]$. Every CSDH case differs from another, whereas systematic reviews and meta-analyses lack the individual approach to CSDH. In systematic reviews all previously published cases of CSDH are gathered together and subjected to the statistical analysis. On the other hand, there are several centres in the UK and the USA where TDC with a local anaesthetic is the initial approach, which is cheaper and globally more efficient $[12,14]$. We retrospectively evaluated surgeons' preferences and to our surprise, TDC was chosen in only 5 cases. This may have resulted primarily from issues with billing the procedure, fear of insufficient anaesthesia, reluctance of the team to perform trepanation outside the operating room and last but not least the unwillingness to try a new technique. However, a survey among European neurosurgeons revealed that TDC can be done successfully by junior residents under supervision [30]. Based on our small sample, which nonetheless is the main drawback of the study, we showed that the decision was primarily made ac- 
cording to the radiological features of CSDH. In our study surgeons more eagerly qualified patients with thicker haematomas and with a smaller midline shift for TDC. The above confirms that we selected radiologically 'simple' cases for the novel approach. However, surgeons achieved good results in treatment of patients with $\mathrm{CSDH}$ when the first choice approach was TDC $[12,14]$. The surgical community's reluctance to adopt novel approaches is particularly noted in urethral robotic surgery, which slowly garners clinical interest [31]. Lack of accessible mentorship and the prolonged/challenging learning curve are known causes of delayed dissemination of new, advanced techniques, despite their clinical validity. Conversely, owing to its simplicity, several undisputed advantages of TDC have been noted. First, general anaesthesia for SC or BHC is associated with some complications, and thus bedside TDC is a good alternative for older patients [14]. Given that the mean age of presentation for a $\mathrm{CSDH}$ is in the sixth decade of life, which is directly linked to comorbidities, patients with diabetes or ischaemic heart disease or taking oral anticoagulants are at significant risk of perioperative and postoperative complications [7, 32]. In that group, a less invasive procedure such as TDC seems to be especially advantageous [15, 20]. Our findings do not support the above statement, as the decision upon selection between TDC, BHC or SC has not been based on clinical characteristics but on radiological findings. The second advantage of TDC is the lower cost of the procedure as well as lower costs of subsequent hospitalisation. The costs associated with TDC are lower than in the case of $\mathrm{BHC}$ or SC. Traditional methods of the evacuation of haematoma are performed in the operating room, which engages numerous medical staff and generates high costs $[10,25,32,33]$. The total cost of the surgical procedure and hospitalisation for a patient harbouring CSDH is estimated at approximately EUR 5000 [25]. However, a disposable TDC set includes all the surgical instruments required for the procedure. In Poland, such a disposable TDC set costs only EUR 400. The patient can be discharged home after follow-up CT in $48 \mathrm{~h}$ following TDC without the need to stay at a high dependency unit [17, 25, 34].

The TDC has some disadvantages. In emergency situations such as intracranial bleeding, there might not be enough time to reach the operating room and perform a craniotomy. However, the risk of intraprocedural bleeding during TDC is extremely low. The recent analysis of 387 procedures at a single-centre revealed one case of significant TDC-related bleeding (0.25\%) [12]. Secondly, there is a risk of incomplete evacuation of the haematoma. The TDC set had a closed-system drainage, though without any irrigation. Nevertheless, a meta-analysis demonstrated that irrigation may lead to better outcomes [27]. Another disadvantage of TDC is certainly the patient's discomfort during the procedure, although that topic was not alluded whereas a single author disagreed with that opinion [15].

Some surgeons have modified traditional TDC sets or used irrigation [4]. The most interesting are modifications of the drilling angle [13, 16, 25, 35]. The burr hole can be placed in the pre-coronal region in order to easily introduce the drain posteriorly. In our study we successfully applied the method proposed by Yadav et al. [16]. In order not to cause vascular injury, another modification of the classic TDC method was introduced [25]. The optimal entry point for TDC has been proposed: $1 \mathrm{~cm}$ anterior to the coronal suture at the level of the superior temporal line [34]. On the other hand, the elevation of the patient's head during and after TDC was proved to have no impact on the rate of recurrence and complications [36].

The third method of CSDH evacuation is SC. The traditional approach to this type of haematoma is particularly useful in septated haematoma or in recurrences [29]. However, according to recent metaanalyses SC is associated with higher morbidity and higher complication rates than craniostomy (12\% vs. $4 \%)$ [3, 37]. In our study almost all patients with septated CSDH were approached (4 SC, $1 \mathrm{BHC}$ ). As proposed by others, craniotomy should be reserved for cases of one or multiple recurrences or where there is a large clot component [7]. If the preoperative CT scan shows that the haematoma is surrounded by a capsule formed by the maturated membranes, TDC is considered to be inappropriate and such patients require SC with membranectomy [19]. In case of any difficulties during bedside TDC, it is more demanding to convert the procedure to SC. Recently endoscopic-assisted membranectomy via BHC was found superior to SC in terms of morbidity rate, mortality rate, recovery time as well as length of hospital stay [22].

\section{Conclusions}

Bedside TDC is a safe and effective alternative to traditional surgical methods of CSDH treatment. By 
means of TDC the patient avoids the operating room and anaesthetic complications and the hospital avoids the high costs of the entire hospitalization. Unless there is septated haematoma, and if the patient is able to tolerate the bedside procedure, TDC should be the recommended technique. A large liquid haematoma with minimal midline shift is easily accessible by TDC and is recommended. In case of haematoma recurrence, presence of a solid capsule or membranes among CSDH, SC remains the best treatment option.

\section{Acknowledgments}

Tomasz Szmuda and Sara Kierońska contributed to a publication equally (first authorship).

\section{Conflict of interest}

The authors declare no conflict of interest.

\section{References}

1. Weigel R, Schmiedek P, Krauss JK. Outcome of contemporary surgery for chronic subdural haematoma: evidence based review. J Neurol Neurosurg Psychiatry 2003; 74: 937-43.

2. Kim SU, Lee DH, Kim Yl, et al. Predictive factors for recurrence after burr-hole craniostomy of chronic subdural hematoma. J Korean Neurosurg Soc 2017; 60: 701-9.

3. Almenawer SA, Farrokhyar F, Hong C, et al. Chronic subdural hematoma management. Ann Surg 2014; 259: 449-57.

4. Bozkurt G, Ayhan S, Akbay A, et al. Treatment of chronic subdural hematoma by twist drill craniostomy with irrigation. Turk Neurosurg 2006; 16: 19-24.

5. Wilberger JE. Pathophysiology of evolution and recurrence of chronic subdural hematoma. Neurosurg Clin N Am 2000; 11: 435-8.

6. De Bonis P, Trevisi G, de Waure C, et al. Antiplatelet/anticoagulant agents and chronic subdural hematoma in the elderly. PLoS One 2013; 8: e68732.

7. DiFiori MM, Lamb LC, Calavan LL, et al. Readmissions in anticoagulated intracranial hemorrhage patients: a retrospective review. World Neurosurg 2018; 110: e305-9.

8. Shoeb M, Fang MC. Assessing bleeding risk in patients taking anticoagulants. J Thromb Thrombolysis 2013; 35: 312-9.

9. Brennan PM, Kolias AG, Joannides AJ, et al. The management and outcome for patients with chronic subdural hematoma: a prospective, multicenter, observational cohort study in the United Kingdom. J Neurosurg 2017; 127: 732-9.

10. Chen JC, Levy ML Causes, epidemiology, and risk factors of chronic subdural hematoma. Neurosurg Clin N Am 2000; 11: 399-406.

11. Ke W, Dongjiang C, Xiangyuan C, et al. A prospective comparative study of twist drill craniostomy versus burr hole craniostomy in patients with chronic subdural hematoma. Turk Neurosurg 2015; 27: 60-5.
12. Jablawi F, Kweider H, Nikoubashman O, et al. Twist drill procedure for chronic subdural hematoma evacuation: an analysis of predictors for treatment success. World Neurosurg 2017; 100: 480-6.

13. Wang QF, Cheng C, You C. A new modified twist drill craniostomy using a novel device to evacuate chronic subdural hematoma. Medicine (Baltimore) 2016; 95: e3036.

14. Seizeur R, Abed-Rabbo F, Obaid S, et al. Chronic subdural haematomas in elderly population. Neurosurgical aspects and focus on the single-burr hole technique performed under assisted local anaesthesia. Br J Neurosurg 2017; 31: 258-61.

15. Lee SJ, Hwang SC, Im SB. Twist-drill or burr hole craniostomy for draining chronic subdural hematomas: how to choose it for chronic subdural hematoma drainage. Korean I Neurotrauma 2016; 12: 107-11.

16. Yadav YR, Yadav S, Parihar VS. Modified twist drill technique in the management of chronic subdural hematoma. Turk Neurosurg 2013; 23: 50-4.

17. Singh SK, Sinha $M$, Singh VK, et al. A randomized study of twist drill versus burr hole craniostomy for treatment of chronic subdural hematomas in 100 patients. Indian J Neurotrauma 2011; 8: 83-8.

18. Lin X. Comparing twist-drill drainage with burr hole drainage for chronic subdural hematoma. Chin J Traumatol 2011; 14: 170-3.

19. Rohde V, Graf G, Hassler W. Complications of burr-hole craniostomy and closed-system drainage for chronic subdural hematomas: a retrospective analysis of 376 patients. Neurosurg Rev 2002; 25: 89-94.

20. Ke W, Dongjiang C, Xiangyuan C, et al. A prospective comparative study of twist drill craniostomy versus burr hole craniostomy in patients with chronic subdural hematoma. Turk Neurosurg 2015; 27: 60-5.

21. Lee JY, Ebel H, Ernestus RI, et al. Various surgical treatments of chronic subdural hematoma and outcome in 172 patients: is membranectomy necessary? Surg Neurol 2004; 61: 523-7.

22. Zhang J, Liu X, Fan X, et al. The use of endoscopic-assisted burrhole craniostomy for septated chronic subdural haematoma: a retrospective cohort comparison study. Brain Res 2018; 1678: 245-53.

23. Smely C, Madlinger A, Scheremet R. Chronic subdural haematoma: a comparison of two different treatment modalities. Acta Neurochir (Wien) 1997; 139: 818-25.

24. Horn EM, Feiz-Erfan I, Bristol RE, et al. Bedside twist drill craniostomy for chronic subdural hematoma: a comparative study. Surg Neurol 2006; 65: 150-4.

25. Lee J, Kim BT, Hwang SC, et al. Indications and surgical results of twist-drill craniostomy at the pre-coronal point for symptomatic chronic subdural hematoma patients. J Korean Neurosurg Soc 2012; 52: 133-7.

26. Xu CS, Lu M, Liu LY, et al. Chronic subdural hematoma management: clarifying the definitions of outcome measures to better understand treatment efficacy - a systematic review and meta-analysis. Eur Rev Med Pharmacol Sci 2017; 21: 809-18.

27. Liu W, Bakker NA, Groen RJM. Chronic subdural hematoma: a systematic review and meta-analysis of surgical procedures. J Neurosurg 2014; 121: 665-73. 
28. Lega BC, Danish SF, Malhotra NR, et al. Choosing the best operation for chronic subdural hematoma: a decision analysis. J Neurosurg 2010; 113: 615-21.

29. Abecassis IJ, Kim LJ. Craniotomy for treatment of chronic subdural hematoma. Neurosurg Clin N Am 2017; 28: 229-37.

30. Baschera D, Tosic L, Westermann L, et al. Treatment standards for chronic subdural hematoma: results from a survey in Austrian, German, and Swiss neurosurgical units. World Neurosurg 2018; 116: e983-95.

31. Mitchell CR, Hendrick RJ, Webster RJ, et al. Toward improving transurethral prostate surgery: development and initial experiments with a prototype concentric tube robotic platform. J Endourol 2016; 30: 692-6.

32. Ramnarayan R, Arulmurugan B, Wilson PM, et al. Twist dril craniostomy with closed drainage for chronic subdural haematoma in the elderly: an effective method. Clin Neurol Neurosurg 2008; 110: 774-8.

33. Chari A, Kolias AG, Santarius T, et al. Twist-drill craniostomy with hollow screws for evacuation of chronic subdural hemat oma. J Neurosurg 2014; 121: 176-83.

34. Hwang SC, Im SB, Kim BT, et al. Safe entry point for twist-drill craniostomy of a chronic subdural hematoma. J Neurosurg 2009; 110: 1265-70.

35. Sucu HK, Gökmen M, Ergin A, et al. Is there a way to avoid surgical complications of twist drill craniostomy for evacuation of a chronic subdural hematoma? Acta Neurochir (Wien) 2007; 149: 597-9.

36. Miele VJ, Sadrolhefazi A, Bailes JE. Influence of head position on the effectiveness of twist drill craniostomy for chronic subdural hematoma. Surg Neurol 2005; 63: 420-3.

37. Peng D, Zhu Y. External drains versus no drains after burr-hole evacuation for the treatment of chronic subdural haematoma in adults. Cochrane Database Syst Rev 2016; 8: CD011402.

Received: 2.11.2018, accepted: 3.02.2019. 